\title{
Application of Psychological Contract in English Film Appreciation Course
}

\author{
Xinmei Wang \\ Shandong University of Finance and Economics, Shandong, China
}

\begin{abstract}
English Film Appreciation Course, as a selective course, has the responsibility of broadening students' horizon and helping them understand world culture better, but the present situation of this course is that the teachers and students usually take it as a pastime, the culture and students' psychological reaction are not given enough attention. This paper tries to discuss the construction of English Film Appreciation Course with the help of psychological contract. It also discusses the forming of psychological contract in the teaching process of English film appreciation course, and then puts forward suggestions on the teaching of the course so as to better carry out similar teaching in the future.
\end{abstract}

Index Terms - psychological contract, English Film Appreciation, elective course

\section{INTRODUCTION}

English Film Appreciation is an important part of the public English curriculum system in colleges and universities. As a special teaching material, the film has an advantage that other carriers, such as paper textbooks, cannot match. Because of effective combination of language, culture, and other information delivery and construction of the real scene of language learning for students through sound, image, and the combination of many elements, this course inspires students' interest in learning and improves the effect of language teaching.

\section{Present Situation of This Course}

In a survey delivered by the author of this paper, more than 87 percent of the students who attended this course wanted to improve their listening and speaking ability, not just take it as an entertainment. And teachers want students to be able to capture the language information as much as possible while appreciating English films, and to experience different cultural elements. In view of the positive psychological expectations of these two aspects, the author intends to analyze and construct the course of English Film Appreciation with the help of psychological contract.

A number of colleges and universities have taken this course into elective courses, but its status is still in a state of being neglected. It is normal for students to take leisure in order to take credit. Teachers mostly choose classic movies and organize the teaching in accordance with the pattern of "watching movies and writing reviews", which leads to the university education's common emphasis on knowledge learning and the neglect of knowledge output. There are few large-scale studies of English film teaching, relative methods and scientific research, so that the unique role of film and television appreciation course has not been discovered, and the teaching effect is not very good. This has led some people to think that this course is not essential.

A. Analysis of Students

1. Being in deep anxiety and suppression

A large number of students lose their orientation after attending college and lack good study habits and effective learning methods. They become more anxious in class, which has a negative effect on their psychology.

2. Lack of interest in learning

Interest is the practical driving force for the exploration of knowledge. If students are interested in learning, they will have positive learning motivation, thus form good study habit and harvest positive learning effect. According to author's survey, only 40 percent of students have a certain interest in English. But there is another phenomenon that cannot be ignored, that is, roughly 95 percent of students expect to improve their English during college life.

3. Low level of speaking and listening ability

Listening and speaking are complementary. The author finds that listening is the Achilles' heel in students' exams, the students also show strong anxiety in listening and speaking classes.

4. Lack of cultural background information

The questionnaire shows that the students have little knowledge of western culture and social background.

\section{B. Analysis of Classroom Teaching}

Considering the importance of culture edification in language learning, as a supplementary course for college English teaching, English film appreciation course is quite popular with the students, almost every university or college has such kind of course. However, in practical teaching, there are many unavoidable problems in this course. For example, 
teachers don't pay enough attention to the interaction with students, most of the time they show entertaining films. After appreciating the film, the students do not have full discussion, so that the input of cultural knowledge quickly fades and even is forgotten. As college English teacher, the author found that, in addition to entertainment or relaxation, many students expect that this course can help them improve their English level and help them understand the culture of English-speaking countries. The problems of this course are as follows:

1. Randomness in selecting textbooks

In selection of the film, the teacher is very casual and lacks the overall thinking and planning. Some colleges and universities, based on their own lecture notes, avoid the problem of randomness, but neglect the time of the works, and the teaching content is not updated for a long time.

2. Separation of course design

As the name implies, this course is composed of appreciation and analysis. Some universities only appreciate not analyze, this course has become appreciation course. Some universities only analyze not appreciate, thus the advantage of the information carrier of this course is completely lost, as a result, it just becomes the variation of intensive reading or extensive reading course.

3. Obsolescence of teaching model

Teachers still have not changed "cramming" teaching mode, and pay no attention to stimulating the students' subjective initiative. Students passively accept knowledge and fail to give full play to the role of their background knowledge and life.

4. Singleness of teaching purpose

Teachers tend to lay much emphasis on the acquisition of words, sentences and texts, ignore the cultivation of students' comprehensive ability. They often think they have finished the teaching task after explaining the words, phrases, grammar and some of the classic lines in the films.

\section{TASKS OF THIS COURSE}

This course is mainly expected to fulfill the following tasks:

\section{A. Enlarge Vocabulary and Improve Listening and Speaking Ability}

The film and television works are from the life, so, through the appreciation of the English film, the students' vocabulary will increase. Vocabulary is the basis of all languages, and only with a certain amount of vocabulary, students can improve their listening and speaking ability accordingly. The language in the movie ranges from pronunciation, intonation, liaison, proverbs, idioms, to even dialects. Coupled with lively images, standard pronunciation, and colorful contents, the English films create a very strong atmosphere of English.

\section{B. Enrich Background Knowledge}

Language learning also includes the understanding of the cultural background behind it. The obstacle of English learning, to a certain extent, is not the language itself, but the understanding of the social and cultural knowledge, and on the ability of analyzing the ideological content of the target language, reasoning, and evaluation. This course really caters to the requirements of context teaching, provides the best learning environment for students, and makes students form the habit of thinking in English language in formal language environment.

\section{Inspire Students' Learning Interest}

Interest is the best teacher. Only if students are interested in the content, will they be willing to learn, have a positive attitude to learning, achieve good learning effect, and form a virtuous cycle of interaction between teachers and students. The wonderful music and wonderful pictures in English movies will encourage students to forget their troubles and pressure and release themselves, which will help stimulate students' interest in learning.

\section{Inspire Students to Think}

The amount of information contained in a movie of about two hours or so is more than an intensive reading of 1000 words. In addition to excellent and living language, shooting angle, the characteristics of the characters and the plot set choreography in English films are all enough to arouse the students' active and comprehensive imagination, thinking and evaluation. Students can be encouraged to analyze movie plot arrangements, review the performance of actors, and to adapt or write the end of the movie based on their own understanding. Teachers can even choose a topic that is strongly debated, and allow students to debate, inspire, train and improve their ability to think.

\section{E. Enrich Teaching Methods}

Traditional English classes mainly focus on comprehensive English teaching materials, with some in-depth argumentative papers, but the content is boring and the teaching methods are relatively monotonous. Because of the vividness of the English films, the teaching methods can be flexible. Facing different genres and styles of film and television teaching materials, teachers can use such colorful teaching methods as dictation, dubbing and role-playing in class. According to the plot of the movie, the students can be guided to describe the plot. In view of the more controversial film and television works, teachers can guide students in heated discussions and hold debates, etc.. 


\section{DeFinition of Psychological Contract}

Psychological contract is a concept based on contemporary research by organizational scholar Denise Rousseau (1989). It represents the mutual beliefs, perceptions, and informal obligations between an employer and an employee. It is distinguishable from the formal written contract of employment which, for the most part, only identifies mutual duties and responsibilities in a generalized form.

Although Rousseau's 1989 article as highlighted by Coyle-Shapiro (2008) "was very influential in guiding contemporary research" (P. 17-34), the concept of psychological contract was first introduced by Argyris (1960) "Since the foremen realize the employees in this system will tend to produce optimally under passive leadership, and since the employees agree, a relationship may be hypothesized to evolve between the employees and the foremen which might be called the 'psychological work contract'. The employee will maintain the high production, low grievances, etc., if the foremen guarantee and respect the norms of the employee informal culture (i.e., let the employees alone, make certain they make adequate wages, and have secure jobs)"(P. 213). However, only within the last ten to fifteen years has it become more popular and more research been done on the subject (Christeen, 2010).

Psychological contracts are formed by beliefs about exchange agreements and may arise in a large variety of situations that are not necessary employer-employee (Rousseau, 1998). These contracts can cause virtuous and vicious circles in some circumstances. Multiple scholars define the psychological contract as a perceived exchange of agreement between an individual and another party (Rousseau, 1998). Psychological contract can be influenced by many things like mutual or conflicting morals and values between employer and employee.

In language teaching, psychological contract relationship is based on expectations, responsibility and love, which are very effective in promoting the relationship between teachers and students. The construction of psychological contract relies on the teacher's role of not only teaching but also cultivating. It helps realize mutual encouragement between teachers and students, pays close attention to the demand of students' growth and development through communication and association, and achieves harmony in relationship between teachers and students. The essence of building of psychological contract relationship is love and confidence, which can be late but should not be absent.

\section{Psychological Contract between Teachers and Students in English Film Appreciation Course}

\section{A. Characteristics of Psychological Contract}

First of all, the psychological contract has the characteristics of the subjectivity. The content of the psychological contract is individual's perception of mutual responsibility, or a kind of subjective feeling, rather than the fact that mutual responsibility itself. The individual has their own unique experience and insights to the relationship between themselves and organizations, as a result, individual psychological contract may do not agree with the content of the employment contract.

Secondly, psychological contract has dynamic characteristics. Formal employment contracts are generally stable and rarely change. But the psychological contract is in a state of constant change and revision. Any change in the way the organization works, whether physical or social, affects the psychological contract. The longer people work in an organization, the wider the scope of the psychological contract covers.

Thirdly, there is a difference between psychological contract and expectation. The psychological contract has not only the expectation, but also the commitment and reciprocity of responsibility and obligation. It includes what employees believe they deserve. Distinguishing between these two concepts has practical significance, and the expectation of the unrealized is mainly the sense of loss. When psychological contract is violated, it produces a stronger negative emotional reaction and follow-up behavior. The core of the psychological contract at this time is an angry emotion, thus employees feel that the organization is perfidious and is treated unfairly.

\section{B. Psychological Contract in English Film Appreciation Course}

Psychological contract is, through a variety of psychological suggestion, to make mutual perception and recognition of their respective expectations without showing in the form of direct and explicit expression, thus form a kind of invisible relationship between rights and obligations of the agreement. Thus, the psychological contract between teachers and students should include the following aspects:

First, both teachers and students have their own psychological expectations. The psychology of teachers and students in this context refers to teachers and students' expectations and expectations of the content and effect of this course.

Second, there is a mutual expectation and a tacit understanding between teachers and students. Not all expectations can be identified and accepted by each other, only when teachers and students accept each other for their own some expectations, can both sides reach a tacit understanding on some aspects of mutual responsibility. It is important to note that the tacit understanding is not always positive. If one side, by suggestion, releases negative signal which is accepted by the other side, a negative tacit understanding even a vicious cycle is formed. As a result, it becomes the main factor affecting the effect of classroom and classroom atmosphere. If the students show their learning attitude through absence from class, sleeping, and the teacher is indifferent, and covey the approval hint to all students, decadent and tacit understanding quickly formed in the class. It can be concluded that a kind of relaxed and active classroom atmosphere needs the joint efforts of both sides between teachers and students, and to prevent the production of a dull classroom 
atmosphere, teachers' unilateral action is particularly important.

Although as an elective course, English film appreciation is not like other required courses which have many requirements, but it does not mean that students and teachers can be in casual and loose state. The mutual expectation among teachers and students is transformed into a mutual rights and obligations relationship. This mutual rights and obligations form a dynamic balance between teachers and students, thus create the effect of "invisible" discipline. Compared with actual discipline, it can play a more normative role in normal classroom order and teaching, which has greater restraint and incentive effect on teachers and students.

\section{Effects of Psychological Contract in Elective Course of English Film Appreciation}

Psychological contract can not only reasonably explain the behavior motivation of individuals and organizations, but also is one of the best ways to improve the efficiency of individual and organizational behavior. The psychological contract between teachers and students is an important factor affecting the behavior and attitude of teachers and students in class. A positive psychological contract is like a link between teachers and students, it not only can reduce the blindness and randomness of the curriculum content arrangements, but also can improve students' satisfaction toward classroom learning, make highly engaged in film English learning, and increase the cohesion of class organization activities.

First, Cohesive function. In Chinese culture, it is generally believed that relationships are more important than written contracts. The important reason for determining the retention of employees is whether the two parties can establish a good psychological contract. Surveys show that the main reason that new employees leave in a year is because they think the organization has failed to deliver on its promises. If he thinks the facts are contrary to expectations, he will choose to leave the company because he thinks that the organization has violated the psychological contract; On the contrary, it will enhance corporative cohesion, generate low turnover rate and high performance. In the same way, in English film appreciation course, the cooperation and satisfaction of expectations from both teachers and students will definitely promote cohesive force.

Second, the restrictive function. The intangible psychological contract in English film appreciation course can regulate the classroom behavior of teachers and students on a deeper level than the tangible discipline. Different from required courses, because of its large number of students, in this course, general discipline can play very limited role. Sometimes, out of consideration of continuity, the break is flexible, so that a great number of students in the process of film show an excuse to leave or skip classes, which interrupt the entire classroom atmosphere. If the teacher can, according to the actual situation of students, set scientific teaching rhythm, choose the works which meet students expect, and reasonably adjust course arrangement according to students' feedback, then students' needs are met, learning interest is triggered, learning enthusiasm is driven, thus reach tacit agreement with the teachers, this kind of psychological contract is obviously better than all the disciplines.

Third, repair function. As mentioned above, students are not interested in English, but hope to express their views in fluent English, which shows the students hold positive psychological expectations; while teaching language knowledge, teachers also want students to cooperate actively, and also have positive psychological expectations. So, in a way, the two kinds of expectations coincide. As for the reason why we did not achieve the ideal state of teaching and learning, it is because of the lack of repair or means of communication. What's more important is how to make the positive psychological expectations between teachers and students a positive strength to encourage both sides to face rather than to avoid the bottleneck of teaching or learning problems. This course is the ideal learning medium, and the theory of psychological contract is the ideal theoretical guidance for the positive psychological expectation between teachers and students.

Fourth, incentive function. Students' learning enthusiasm and degree of cooperation were positively correlated with the attractiveness and interest of the films shown in the class. In other words, if a student is interested in the film shown, the information the teacher introduced, and the discussion in which they were involved last class, they will take positive attitude to meet the learning in the following class. Therefore, the teacher can fully take advantage of students' positive psychology to respond to students' classroom learning.

\section{Construction of Psychological Contract in Elective Course of English Film ApPreciation}

Rousseau (1989) believes that the construction of the psychological contract is an understanding of each other's rights and obligations, or the construction of relevant beliefs. While the scholars argue about the nature of the concept of psychological contract, they also carry out extensive research on its contents. According to the empirical study of Robinson et al. (1996), employees believe that the organization's obligations are mainly summarized as: rich content, fair pay, growth and promotion opportunities. Employees believe that their obligations mainly focus on their loyalty, overtime work, volunteer work, and job transfer, etc. After analyzing the organization and its obligations, they found two common factors: transactional factors and relational factors. In other words, psychological contract is divided into two main categories: transactional psychological contract and relational psychological contract. They differ in focus, time frame, stability, scope and clarity (Rousseau, 1995). Recent research has shown that psychological contracts can be recognized from three aspects: transactional obligation, training obligation, and relational obligation. In English film appreciation course, we can construct the class from the following aspects: 


\section{A. Transactional Obligation}

Transactional obligation focuses more on the explicit elements of the contract without accounting much for intrinsic qualities of workers. It is based on the direct exchange, both sides have clear and specific purpose and expect immediate rewards. Because of the elective nature of this course, the transactional psychological contract has been established once students have chosen this course on the elective system. Students expect to learn something and earn credits from teachers by promising attendance, following disciplines and fulfilling requirements of this course. Therefore, in the first class, it is very necessary for teachers to make clear about what will be introduced, what can they learn from this course, and emphasize the necessity and importance of disciplines and the relevant punishments of violation of discipline, clear performance evaluation methods, so as to eliminate their doubts and make them clear about this course. During the whole semester, the teacher shall strictly fulfill the teaching task, strengthen the supervision of attendance and the evaluation of the performance of the classroom, and realize the students' long-term and effective "self-discipline". Of course, the transactional obligation can only play a limited role in controlling absences and skipping classes and so on, which is a less stable and lower psychological contract.

\section{B. Relational Obligation}

Relational obligation stresses interdependence of the organization and level of social exchange. In this course, it is based on the emotional exchange between teachers and students and more stable, and once the stability is formed, students of this kind of psychological contract have higher degree of cooperation and loyalty to classroom activities. In contrast to the constraining effect of the transactional obligation, the relational psychological contract can play a stimulating role. For quite a number of students, the purpose of taking the course is to relieve anxiety, regulate the tense rhythm of life, and improve expressive ability. Teachers should make full use of students' psychological demand to create active, effective and lively classroom atmosphere, stimulate students' interest in learning English. The author found that the students are more interested in the latest release of blockbusters, thrillers, comedy, such as campus romance films. Therefore, the main objective of the appreciation is to focus on the above subject matters, which will be really conducive to the perfect combination of teaching and learning. In addition, the communication between teachers and students is also an important way to construct a relational psychological contract.

\section{Training Obligation}

Training Obligation is a kind of dynamic and open psychological contract. It largely depends on teacher's high quality of teaching and students' high quality of acquisition of knowledge. Both sides have high expectations for each other. Among the students in the English Film Appreciation course, there are quite a few students who have chosen this course for purely academic purposes. They either want to improve their listening or spoken English, or hope to further strengthen their English level, or want to learn the new ideas and ways of thinking, or want to know about western language and culture. In short, they hope that this course will provide long-term benefits for their future development. Students with such high expectations can't satisfy their thirst for knowledge if only show them some entertainment films. This requires teachers to make the content of the classroom more interesting and informative to give them specialized and high-quality training. In the process of film appreciation, we can select the video clips with larger amount of knowledge, stronger cultural representation and richer language materials to have deep explanation and discussion. At the same time, according to different students' interest, students can be divided into a number of different study groups, the study group can assume different spoken English, listening, and learning tasks to practice, teacher can also give them corresponding guidance. In addition, the teachers should also train themselves and strengthen their own professional skills, choose movies of different categories, and according to students' classroom reaction, adjust course content, promote the psychological contract between teachers and students.

\section{CONCLUSION}

To summarize, students' learning interest and enthusiasm were aroused by teachers' performing their desired behavior and improving their teaching quality, while students' learning initiative and efficiency might be ruined when teacher's desired behavior lost. Psychological contract, a special contract form, is based on the emotional communication and reaches an invisible agreement about rights and obligations. The results in this paper reflect that psychological contract between teachers and students has a good application value in the teaching of English Film Appreciation course.

\section{REFERENCES}

[1] Cohen, A. D. (2000). Strategies in Learning and Using a Second Language. Beijing: Foreign Language Teaching \& Research Press.

[2] Coyle-Shapiro, Jacqueline A-M. and Parzefall, M. (2008). Psychological contracts. In: Cooper, Cary L. and Barling, Julian, (eds.) The SAGE handbook of organizational behavior. London: SAGE Publications, 17-34.

[3] Chris Argyris. (1960). Understanding Organizational Behavior. Homewood, IU.: Dorsey Press.

[4] Denise M. Rousseau. (2016). Schema, promise and mutuality: The building blocks of the psychological contract. Journal of Occupational and Organizational Psychology. 74, 511-541. 
[5] George, Christeen. (2010). Psychological Contract: Managing and Developing Professional Groups. Maidenhead, GB: Open University Press.

[6] Rousseau, Denise M. (1998). The 'Problem' of the Psychological Contract Considered. Journal of Organizational Behavior, 19, 665-71.

[7] Rousseau D. M. (1995). Psychological Contracts in Organizations: Understanding written and Unwritten Agreements. California: Sage Publications.

[8] Rousseau, D. M. (1989). Psychological and implied contracts in organizations. Employee Responsibilities and Rights Journal, 2 , 121-139.

[9] Sandra L. Robinson. (1996). Trust and Breach of the Psychological Contract. Administrative Science Quarterly, 41, 574-599.

Xinmei Wang was born in Dezhou, China in 1977. She received her master degree in linguistics from Chongqing University, China in 2004.

She is a College English teacher for English majors in Shandong University of Finance and Economics in Jinan, has been teaching English majors for more than 10 years. The courses she has taught include Advanced English, Basic English Writing, etc. During this decade, she published several papers. Her research field is theoretical linguistics. 